\title{
Crisis management during anaesthesia: hypertension
}

\author{
A D Paix, W B Runciman, B F Horan*, M J Chapman, M Currie
}

Qual Saf Health Care 2005;14:e12 (http://www.qshc.com/cgi/content/full/14/3/e12). doi: 10.1136/qshc.2002.004127

See end of article for authors' affiliations

.....................

Correspondence to: Professor W B Runciman, President, Australian Patient Safety Foundation, GPO Box 400, Adelaide, South Australia 5001 Australia; research@apsf. net.au

Accepted 11 January 2005
Background: Hypertension occurs commonly during anaesthesia and is usually promptly and appropriately treated by anaesthetists. However, its recognition is dependent on correctly functioning and calibrated monitors. If it is not diagnosed and/or promptly corrected, it has the potential to cause significant morbidity and even mortality.

Objectives: To examine the role of a previously described core algorithm "COVER ABCD-A SWIFT $\mathrm{CHECK}^{\prime \prime}$ supplemented by a specific sub-algorithm for the management of hypertension occurring in association with anaesthesia.

Methods: The potential performance of this approach for each of the relevant incidents among the first 4000 reported to the Australian Incident Monitoring Study (AIMS) was compared with the actual management as reported by the anaesthetists involved.

Results: There were 70 reports of intraoperative hypertension among the first 4000 incidents reported to AIMS. Drug related causes accounted for $59 \%$ of all incidents. It was considered that, properly applied, this structured approach would have led to a quicker and/or better resolution of the problem in $21 \%$ of the cases.

Conclusion: Once hypertension is identified and confirmed, its rapid control by the careful use of a volatile anaesthetic agent, intravenous opioids, or rapidly acting antihypertensives will usually avoid serious morbidity. If hypertension is unresponsive to the treatment recommended in the relevant sub-algorithm, an unusual cause such as phaeochromocytoma, carcinoid syndrome, or thyroid storm should be considered.
1 ntraoperative hypertension is common and has many causes. It is usually rapidly and successfully treated by anaesthetists. However, when it is severe, no cause is evident, or it fails to respond to routine measures, it has the potential to cause morbidity and even mortality in susceptible patients. ${ }^{12}$ A rapid appropriate response by the anaesthetist to this problem is therefore required. Because management may be delayed and variable, it was decided to examine the place of a structured approach to hypertension occurring in association with anaesthesia.

In 1993 a "core" crisis management algorithm represented by the mnemonic COVER ABCD-A SWIFT CHECK (the AB precedes COVER for the non-intubated patient) was proposed as the basis for a systematic approach to any crisis during anaesthesia where it is not immediately obvious what should be done or where actions taken have failed to remedy the situation. ${ }^{3}$ This was validated against the first 2000 incidents reported to the Australian Incident Monitoring Study (AIMS). AIMS is an ongoing study which involves the voluntary anonymous reporting of any unintended incident which reduced or could have reduced the safety margin for a patient. $^{4}$

It was concluded that, if this algorithm had been correctly applied, a functional diagnosis would have been reached within 40-60 seconds in 99\% of applicable incidents, and the learned sequence of actions recommended by the COVER portion would have led to appropriate steps being taken to handle the $60 \%$ of problems relevant to this portion of the algorithm. ${ }^{3}$ However, this study also showed that the $40 \%$ of problems represented by the remainder of the algorithm ABCD-A SWIFT CHECK were not always promptly diagnosed or appropriately managed..$^{3-5}$ It was decided that it would be useful, for these remaining problems, to develop a set of subalgorithms in an easy-to-use crisis management manual. ${ }^{6}$ This study reports on the place of the COVER ABCD-A SWIFT CHECK algorithm in the diagnosis and initial management of hypertension, provides an outline of a specific crisis management sub-algorithm for hypertension during anaesthesia, and indicates the potential value of using this structured approach.

\section{METHODS}

Of the first 4000 incidents reported to AIMS, those that made reference to hypertension were extracted and analysed for relevance, the presumed precipitating cause, the type of anaesthetic technique employed, the management, and outcome. The COVER ABCD-A SWIFT CHECK algorithm, described elsewhere in this series of articles, ${ }^{6}$ was applied to each relevant report to determine the stages at which the problem might have been diagnosed and to confirm that activating the COVER portion would have led to appropriate initial steps being taken. As hypertension is not always adequately dealt with by this algorithm, a specific subalgorithm was developed (see fig 1) and its putative effectiveness was tested against the reports. How this was done is described elsewhere in this series of articles. ${ }^{6}$ The potential value of this structured approach-that is, the application of COVER ABCD-A SWIFT CHECK to the diagnosis and initial management of this problem followed by the application of the hypertension sub-algorithm-was assessed in the light of the AIMS reports by comparing its potential effectiveness for each incident with that of the actual management as recorded in each report.

\section{RESULTS}

Among the first 4000 AIMS reports there were 252 in which hypertension was mentioned; 182 incidents were excluded from further analysis. Of these, 154 referred only to hypertension diagnosed preoperatively which was unrelated to the event giving rise to the report, 11 dealt with hypertension occurring only in recovery, 10 reported hypertension secondary to laryngoscopy and endotracheal

* Dr Horan died before this research was published. 


\section{HYPERTENSION}

\author{
PRECIPITATING FACTORS (1)* \\ Give particular consideration to: \\ Drug errors (1) \\ Awareness or light anaesthesia (2) \\ Pre-existing hypertension (3) \\ Airway problems (4) \\ Surgical factors (5) \\ Hypercarbia (6) \\ Unusual/uncommon conditions \\ Phaeochromocytoma \\ Hyperthyroidism \\ Malignant hyperthermia \\ Raised intracranial pressure \\ Fluid overload
}

\section{EMERGENCY MANAGEMENT}

Complete COVER ABCD-A SWIFT CHECK (7)

Confirm the blood pressure change is real (8)

Deepen anaesthesia/assess depth

Specifically consider vasopressors, stop them (9)

Inform and interrogate the surgeon; cease stimulation

Recheck for drug errors and delivery of anaesthesia

Consider an appropriate dose of opioid (10)

Consider antihypertensive therapy:

\section{BE CAUTIOUS USING HYPOTENSIVE AGENTS IF THE POSSIBILITY OF LIGHT ANAESTHESIA EXISTS}

Consider GTN $50 \mathrm{mg}$ in $500 \mathrm{ml} 5 \%$ dextrose and start at $0.1 \mathrm{ml} / \mathrm{kg} / \mathrm{hr}$ (adult dose $5-10 \mathrm{ml} / \mathrm{hr}$ )

If tachycardia is troublesome: Give atenolol $0.015 \mathrm{mg} / \mathrm{kg}$ by IV bolus injections (11)

Titrate drugs against effect

The sub-algorithm forms a facing page of the

Crisis Management Manual 10.

* Numbers in brackets refer to Notes in the right hand panel.

\section{FURTHER CARE}

Review and treat probable cause(s)

See precipitating factors and (1) to (9) below

Resolution will usually follow

Consider invasive blood pressure monitoring

\section{NOTES:}

It was judged that correct use of COVER ABCD followed by the hypertension sub-algorithm would have identified the specific cause in $79 \%$ of 70 relevant incidents reported to AIMS. In $21 \%$ no obvious cause was apparent, but was assumed to be a combination of light anaesthesia and/or excessive surgical stimulation and in all cases was effectively treated by rapidly deepening anaesthetic depth.

(1) Drug errors, secondary to drugs being given $-40 \%$, or following drugs unintentionally not being given $-14 \%$.

(2) Presumed light anaesthesia $-21 \%$ of reports. Due to inter-individual variation, failure to deliver agents: vaporiser, nitrous oxide, syringe driver failure.

(3) Preoperative hypertension $-61 \%$ of the 252 reports received by AIMS.

(4) Causes included hypoventilation, hypercarbia and hypoxia.

(5) Surgical stimulus, water intoxication, aortic cross clamping.

(6) Hypercarbia in $11 \%$. Due to hypoventilation, soda lime exhaustion, sticking valve in circle system, inadequate fresh gas flows in non rebreathing circuits.

(7) Use of the COVER ABCD-A SWIFT CHECK algorithm identified $73 \%$ of incidents reported to AIMS.

(8) Use a sphygmomanometer and auscultate the blood pressure. When using an arterial line, check the zero and calibration. In $4 \%$ of cases the hypertension was serious.

(9) Inadvertent vasopressor administration was the commonest reported cause $-40 \%$.

(10) After reviewing the drugs administered to date, give opioids if judged appropriate, i.e. fentanyl $0.25-0.5 \mathrm{mcg} / \mathrm{kg}$ aliquots, titrated to effect.

(11) Esmolol, a $\beta$ blocker with a rapid onset and short duration of action, in a dose of $0.25-0.5 \mathrm{mg} / \mathrm{kg}$ may be a better choice if available.

\section{These notes comprise a reverse side of a page of the}

Crisis Management Manual 10.

\section{Figure 1 Hypertension.}

intubation, and three involved hypertension which was a consequence of poorly controlled preoperative hypertension. Four reports of spurious hypertension (table 1) were each due to equipment malfunction. All of these were excluded, leaving 70 reports of the 252 for analysis.

These remaining 70 reports were analysed for causes, treatment, and outcome from the hypertensive incident. The precipitating factors were most commonly drug related (41 reports, 59\%), excessive surgical stimulation or light anaesthesia ( 15 reports $(21 \%)$, of which 13 were during general anaesthesia and two during regional anaesthesia), or equipment related (nine reports, 13\%). Miscellaneous causes accounted for the remaining five reports (7\%); these included two reports of water intoxication and one report each of

\begin{tabular}{|lc|}
\hline Table 1 Causes of spurious hypertension \\
\hline Cause of hypertension & $\begin{array}{c}\text { No of } \\
\text { incidents }\end{array}$ \\
\hline Calibration drift of invasive device & 2 \\
Sphygmomanometer cuff herniation & 1 \\
Calibration error of non-invasive device & 1 \\
Total & 4 \\
\hline In all cases the error was detected by the use of a \\
sphygmomanometer to auscultate the blood pressure. \\
\hline
\end{tabular}

carcinoid syndrome, pre-eclampsia and phaeochromocytoma. Table 2 shows the drug related causes and table 3 the equipment related causes.

In the majority of cases the anaesthetist deepened anaesthesia or corrected the primary cause-for example, repositioning the malpositioned vaporiser in six cases. In 22 cases $(31 \%)$ specific intravenous antihypertensive therapy

\begin{tabular}{|c|c|}
\hline Cause of hypertension & No of incidents \\
\hline \multicolumn{2}{|l|}{ Vasopressor administration: } \\
\hline $\begin{array}{l}\text { inadvertent, by anaesthetist } \\
\text { by a surgeon }\end{array}$ & $\begin{array}{r}16 \\
6\end{array}$ \\
\hline IV adrenaline with local anaesthetic* & 6 \\
\hline \multicolumn{2}{|l|}{ Anaesthetic failure: } \\
\hline failure to deliver volatile agent† & 6 \\
\hline failure to deliver nitrous oxide & 4 \\
\hline Unknown $\ddagger$ & 3 \\
\hline Total & 41 \\
\hline \multicolumn{2}{|c|}{$\begin{array}{l}\text { *Associated with epidural injection }(n=3) \text {, interscalene } \\
\text { blocks }(n=2) \text {, cervical plexus block }(n=1) \text {. } \\
\text { †All six due to malpositioning of the vaporiser. } \\
\text { fln three reports drug problems were mentioned but there } \\
\text { were insufficient data for analysis. }\end{array}$} \\
\hline
\end{tabular}


Table 3 Equipment related causes of intraoperative hypertension

\begin{tabular}{ll}
\hline Cause of hypertension & No of incidents \\
\hline Ventilation problem: & 3 \\
Stuck valve & 3 \\
Hypoventilation & 2 \\
Soda lime exhaustion & 1 \\
Endobronchial intubation & 9 \\
Total &
\end{tabular}

was administered. A range of agents was used. Serious morbidity occurred in six cases; there were two reports each of myocardial infarction, pulmonary oedema, and awareness under general anaesthesia.

When the COVER ABCD-A SWIFT CHECK algorithm was applied to each report, it was considered that all cases of hypertension would have been detected at the SCAN level. It was considered that the cause of the hypertension, once identified, would have been detected at the Vl stage of COVER in $4 \%$ (hypercapnia due to hypoventilation), at the V2 stage of COVER in $9 \%$ (vaporiser not correctly seated on the back bar), at the El (endotracheal tube) stage of COVER in $1 \%$ (inadvertent endobroncheal intubation), at the recheck/ review stage of COVER in $20 \%$, and at the D (drugs stage) of $\mathrm{ABCD}$ in $39 \%$. Of the remaining 19 reports where a diagnosis was not made, it was considered that, in three cases, "spurious" hypertension secondary to pressure measuring device faults would have been detected at the $\mathrm{R}$ stage of COVER. In one other case there was a calibration error of a non-invasive measurement device. In the remaining 15 reports of the $19(79 \%)$, no specific cause was identifiable at the time of reporting or upon consideration of the incident by AIMS reviewers. These results are summarised in table 4 .

When the potential effectiveness of the structured approach represented by the COVER ABCD-A SWIFT CHECK algorithm and the special sub-algorithm for hypertension (fig 1) was compared with that of the actual management as documented in each of the 70 incidents, it was considered that, properly applied, the structured approach would have led to a quicker and/or better resolution of the problem in 15 cases $(21 \%)$.

\section{DISCUSSION}

Hypertension is commonly encountered by anaesthetists, being mentioned in $252(6 \%)$ of the first 4000 incidents reported to AIMS. Of these reports, 154 mentioned preoperative hypertension only. Pre-existing hypertension, particularly if untreated, increases the likelihood of intraoperative hypertension and of complications, as has previously been reported..$^{7}$ Hypertension is common. The Framingham Study found that $20 \%$ of urban "whites" had blood pressures

Table 4 Level of identification of cause using the algorithm

\begin{tabular}{ll}
\hline Level & No (\%) \\
\hline V1 ventilation & $3(4)$ \\
V2 vaporiser & $6(9)$ \\
E Equipment & $1(1)$ \\
R Review/Recheck & $14(20)$ \\
D Drugs & $27(39)$ \\
Unidentified* & $19(27)$ \\
Total & $70(100)$ \\
\hline
\end{tabular}

*In 15 cases no specific cause could be identified by the AIMS reviewers and in four cases a cause was attributed (see text). greater than $160 / 95 \mathrm{~mm} \mathrm{Hg}$, and almost half had pressures greater than 140/90 mm Hg. The incidence was even higher in "non-whites".

A reliable and early diagnosis of hypertension is only possible with accurate, regularly repeated measurements of systemic blood pressure. Monitor accuracy is dependent on correct maintained calibration of the zero point and on linearity throughout the measurement range. This is emphasised by the three cases in which spurious hypertension was recorded by invasive $(\mathrm{n}=2)$ and non-invasive $(\mathrm{n}=1)$ monitors due to calibration problems and one further report of a sphygmomanometer cuff bladder herniation giving rise to an erroneously high blood pressure.

Hypertension and tachycardia under anaesthesia have been shown to be independent risk factors for poor outcomes, particularly after long procedures.

Analysis of the AIMS reports has served to emphasise the fact that, while hypertension is usually readily detected and correct identification and treatment of the primary cause usually follows rapidly, a structured systematic approach is necessary to optimise management and outcome in atypical cases. It was judged that correct use of the COVER ABCD-A SWIFT CHECK core algorithm and the hypertension subalgorithm would, properly applied, have led to earlier recognition and/or better management in $21 \%$ of relevant incidents reported to AIMS.

All cases of hypertension should be detected at the SCAN level and confirmed with a manual verification at the CHECK level of the COVER algorithm. The COVER portion of the algorithm yielded 34\% of the causes; a further 39\% were due to drug errors and would have been detected during the $\mathrm{ABCD}$ portion of the algorithm; $27 \%$ of causes of hypertension in this series remained undiagnosed. The sub-algorithm

\section{Key messages}

- There were 70 incidents of intraoperative hypertension analysed from among the first 4000 reports to the AIMS database.

- In $41(59 \%)$ of the analysed reports drugs were the precipitating cause.

- Excessive surgical stimulation or light anaesthesia accounted for another 15 reports (21\%).

- There were nine reports (13\%) involving equipment related causes.

- Serious morbidity (six cases) involved two each of myocardial infarction, pulmonary oedema, and awareness under general anaesthesia.

- A reliable early diagnosis of hypertension during anaesthesia is dependent upon accurate repeated measurements of systemic blood pressure and monitor accuracy. The latter is dependent upon correct maintained calibration and linearity throughout the measurement range.

- Once diagnosed, rapid control of hypertension (titration of volatile agent or of intravenous opioids or rapidly acting antihypertensives) is necessary to avoid potentially serious morbidity.

- In this series it was considered that, properly applied, the structured approach using the COVER ABCD-A SWIFT CHECK algorithm and the specific sub-algorithm for hypertension would have led to a quicker and/or better resolution of the problem in 15 cases (21\%). 
presented in fig 1 was relatively ineffective (four of 19 reports) at identifying the cause of the problem. However, in all cases, control of blood pressure would have been achieved by following the steps recommended in the hypertension sub-algorithm.

The use of the COVER ABCD algorithm will identify and treat the cause of hypertension in the majority $(60 \%)$ of cases. However, the use of the sub-algorithm specific for hypertension would have been required in the $40 \%$ of reports in which this did not lead to resolution of the problem. In those instances where no obvious cause could be identified, it should be assumed to be due to a combination of light anaesthesia and/or excessive surgical stimulation and the patient depth of anaesthesia rapidly deepened. This will constitute effective treatment for the great majority of cases of hypertension where the cause remains obscure.

Hypertension can have serious consequences for the patient. Major morbidity occurred in six patients and consisted of two reports each of myocardial infarction, pulmonary oedema and awareness while under general anaesthesia. Once identified and confirmed, hypertension should rapidly be controlled by increasing volatile agent concentration or by titrating intravenous doses of opioids or rapidly acting antihypertensives. Failure to respond should alert the anaesthetist to the possibility of an overlooked or unusual cause. The complete algorithm should be carefully repeated at this stage. Should no cause be found, unusual conditions such as phaeochromocytoma, carcinoid syndrome, or thyroid storm should be considered.

Finally, it is important that a full explanation of what happened be given to the patient, that the event and the results of any tests should be documented in the anaesthetic record and that, if appropriate, the patient be given a letter to warn future anaesthetists. If a particular precipitating event was significant or a particular action was useful in resolving the crisis, this should be clearly explained and documented.

\section{ACKNOWLEDGEMENTS}

The authors would like to thank all the anaesthetists in Australia and New Zealand who contributed to the 4000 incident reports upon which this and the other 24 papers in the Crisis Management Series are based. The coordinators of the project also thank Liz Brown for preparing the draft of the original Crisis Management Manual; Loretta Smyth for typing; Monika Bullock RN for earlier coding and classifying of data; Dr Charles Bradfield for the electronic version of the algorithms; Dr Klee Benveniste for literature research; and Drs Klee Benveniste, Michal Kluger, John Williamson and Andrew Paix for editing and checking manuscripts.

\section{Authors' affiliations}

A D Paix, Consultant Anaesthetist, Princess Royal University Hospital, Orpington, Kent, UK

W B Runciman, Professor and Head, Department of Anaesthesia and Intensive Care, University of Adelaide and Royal Adelaide Hospital, Adelaide, South Australia, Australia

B F Horan, Senior Staff Specialist, Department of Anaesthesia, St Vincent's Hospital, Darlinghurst, New South Wales, Australia M J Chapman, Senior Staff Specialist, Intensive Care Unit, Royal Adelaide Hospital and University of Adelaide, Adelaide, South Australia, Australia

M Currie, Clinical Quality Co-ordinator, Goulburn Base Hospital, Goulburn and Consultant in Clinical Quality, Southern Area Health Service, New South Wales, Australia

This study was coordinated by the Australian Patient Safety Foundation, GPO Box 400, Adelaide, South Australia 5001, Australia.

\section{REFERENCES}

1 Reich DL, Bennett-Guerrero E, Bodian CA, et al. Intraoperative tachycardia and hypertension are independently associated with adverse outcome in noncardiac surgery of long duration. Anesth Analg 2002;95:273-7.

2 Wongprasartsuk P, Sear JW. Anaesthesia and isolated systolic hypertension: pathophysiology and anaesthesia risk. Anaesth Intensive Care 2003;31:619-28.

3 Runciman WB, Webb RK, Klepper ID, et al. Crisis management: validation of an algorithm by analysis of 2000 incident reports. Anaesth Intensive Care 1993;21:579-92.

4 Webb RK, Currie M, Morgan CA, et al. The Australian Incident Monitoring Study: an analysis of 2000 incident reports. Anaesth Intensive Care 1993;21:520-8.

5 Webb RK, van der Walt JH, Runciman WB, et al. Which monitor? An analysis of 2000 incident reports. Anaesth Intensive Care 1993;21:529-42.

6 Runciman WB, Kluger MT, Morris RW, et al. Crisis management during anaesthesia: the development of an anaesthetic crisis management manual. Qual Saf Health Care 2005; 14:e1.

7 Prys-Roberts C. Hypertension and anaesthesia - fifty years on. Anaesthesiology 1979;50:281-4.

8 Foster ED, Davis KB, Carpenter JA, et al. Risk of noncardiac operation in patients with defined coronary artery disease: the Coronary Artery Surgery Study (CASS) registry experience. Ann Thorac Surg 1986;41:42-50.

9 Dannenberg AL, Garrison RJ, Kannel WB. Incidence of hypertension in the Framingham study. Am J Public Health 1988;78:676-9

10 Australian Patient Safety Foundation. Crisis Management Manual: COVER $A B C D$ A SWIFT CHECK. Adelaide: Australian Patient Safety Foundation, 1996, 74 pp. Available at http://www.apsf.net.au/anaesthesia.htm (accessed 6 September 2004). 